\title{
The Application of Constructivism Teaching Theory in College Piano Teaching
}

\author{
Yufang Guo \\ Ningxia Art Vocational College, China. \\ 617626196@qq.com
}

Keywords: College, piano teaching, constructivism, teaching method.

\begin{abstract}
The purpose of this study is to explore the application of constructivism teaching theory in college piano teaching. Based on the theory of constructivism, and combined with the current situation of piano teaching in universities in china, the new method of piano teaching is explored. By analyzing the problems of piano teaching in colleges and universities, some corresponding solutions are put forward from the aspects of students, teaching methods and teachers. The results show that constructivist teaching method can stimulate students' interest in learning and improve their learning efficiency. Therefore, we can conclude that constructivism teaching method is suitable for piano teaching practice in colleges and universities.
\end{abstract}

\section{Introduction}

Since the 80 s of last century, technology has been changing. This not only puts forward new challenges to the traditional teaching mode of colleges and universities, but also puts forward higher requirements for college music teaching [2]. In this context, many foreign researchers have proposed the application of constructivism in music teaching. For the status of constructivist education in today's world, American scholar Brooks has done an overview [7]. Not long ago, constructivism remained only in the realm of consciousness in the superstructure. However, it has been mentioned in many modern journals on educational reform. Since 1980, constructivism has been the most influential psychological theory in science curriculum [3].

At present, the piano education in our country has developed vigorously. However, in many colleges and universities, there are still many shortcomings in piano teaching and learning [6]. The teaching model is inconsistent with the demand for talent training. Many colleges and universities copy the teaching mode and content of professional music colleges [1]. Some teachers are not clear about the target of talent training in the school. The teacher only focuses on piano playing skills, rather than a comprehensive music literacy. This leads to the lack of emotional experience and the improvement of aesthetic level. Teaching methods are too old and single. In the teaching process, teachers generally use the traditional teaching methods, that is, the collective teaching. On the one hand, it neglected the cultivation of students' interest and creativity and imagination. On the other hand, it cannot teach students in accordance with their aptitude, and cannot achieve the best learning effect. In the classroom, teachers and students lack communication and interaction [4]. The teacher is the main body of the classroom, and the students passively accept the knowledge. The teaching evaluation system is not comprehensive enough, and it is too one-sided and single.

Facing the problems of teaching and learning in the field of piano in China, some scholars have suggested that piano teaching should continue to innovate and break through the previous model. To this end, we should do the following aspects [5]. First, the teacher should combine the educational theory of the piano with the teaching practice, guide the exploration of the beauty of the learners, and then make their own quality develop in an all-round way. Second, teachers should implement teaching at different levels so that students can have a systematic knowledge of piano culture. Third, the teacher should build a practical piano teaching system, which can systematically develop learners' judgment and playing ability. 


\section{State of the Art}

The concept of constructivism is not only prevalent in the domestic academic circles, but also popular in foreign countries. This can be seen in many ways. The basic principles of constructivism are applied in practical teaching and learning, including the humanities and social sciences. It has achieved some success. There are many studies abroad to apply constructivism to music teaching. These research theories are closely integrated with the practice of music teaching. It not only enriches the theory of music teaching, but also has instructive significance for the teaching content and teaching methods in the music class. In today's western countries, there is a strong criticism of the past teacher education model. It thinks that it only focuses on imparting the principles of education and teaching content, which is far from reality. For example, German scholar Hart believes that the former teaching philosophy still plays a major role in nurturing teachers. In other words, the teaching material of the theory can hardly be reflected in the actual examination [8]. The discussion of teaching theory is relatively isolated from each other and stands in their respective positions. They ignore the reality and work without thinking. In the reform of teacher education, the western developed countries have been in the lead, but the effect is not so obvious. There is a contradiction. On the one hand, many scholars are actively engaged in the study of constructivism; on the other hand, they engage in a rigid and unrealistic educational model. Compared with the domestic, although the application of constructivism in the piano has not been mature in the teaching of music, the attention of this kind of research is still very high. In addition, at present, the application research of constructivism in music teaching only stays in the superficial change, and has not touched the deeper research results. In the practice of piano teaching, it is difficult to put forward very good suggestion [9]. Quite a few countries have applied constructivism widely in the practice of piano research. Learning is the process of students' self-construction cognition. The perfect knowledge system is just a pile of theories, so learners should build up their own knowledge of the real world. There are many studies on the practical behavior of piano teaching as an experimental method of constructivism, and they also draw good conclusions.

At present, the research on constructivism is mainly concentrated in the psychology and educational circles in China. In the field of music teaching, the practical research in the field of piano teaching is still in the initial stage, and yet to be developed. This is the basis of some theoretical research in this paper. If the application of constructivism in piano teaching is taken as the key word, we can find that there are only six papers in this field. Among them, a half of the main content is to analyze and study the curriculum system, and the other three are to study piano teaching in teacher's college. Moreover, few citations and download times show that few people pay attention to it [10]. From the above analysis, we can see that the importance of constructivism is not emphasized in the teaching of piano at home. It lacks research related to it. The literature simply quotes the theory of constructivism and its application to the transformation of teaching models. Piano education should be based on the specific circumstances of different students, including hobbies, knowledge, skills, personality types and so on. Teachers should explore and apply more advanced teaching models, and make full use of modern information technology and combine modern and excellent educational ideas and theories to replace the old teaching ideas. In the piano teaching, teachers should make full use of the students' curiosity and thirst for knowledge, arouse students' enthusiasm and initiative, so that the students can achieve efficient combination of theory and performance in the process of learning the piano. To sum up, in the piano teaching in colleges and universities, both in theory and practice, we should explore vast space for development, and carry out a series of new exploration. Constructivism paradigm of teacher education is a scientific and advanced concept in the world, but it has not been widely applied. Liu Wei has made a brief introduction to the paradigm of teacher education [11]. In her view, there are many basic paradigms of teacher education in the world, including the reflective paradigm, the constructivist paradigm, the emotional paradigm, the critical paradigm, and the capacity paradigm. In order to adapt to the policy of national informatization construction, our country has carried on the reform in the education, and has carried on some reform attempts to the teacher's post service training. Constructivism was introduced into some teacher training and training programs, and a new training 
model was adopted. In this reform practice, the representative is professor Chen Xiangming. She believes that although the concept of participatory teacher training has been widely recognized and widely deployed in the experimentation area, the use of this approach is uncertain.

\section{Methodology}

\subsection{An overview of constructivism and its related theories}

Gvico, the philosopher of Italy, put forward the idea of constructivism first. His view is that all knowledge is constructed by learners. Any study of new knowledge is based on existing knowledge. New knowledge and existing knowledge are interrelated and influence each other. This kind of learning is not a disorderly pile up. From the perspective of philosophy, constructivism can be traced back to the synthesis of Kant's rationalism and empiricism. In his opinion, the cognitive subject can construct the basic cognitive principle, organize experience and develop knowledge internally, so as to make up for the lack of direct access to the outside world. In the history of the development of education, the change of constructivism has its profound origin. It is mainly derived from the study of J. Piaget and Vygotsky in switzerland. They believe that when people's information is new and unbalanced, their knowledge will change, and they all advocate the use of mixed ability learning grouping to promote cognitive change. The view of contemporary constructivism mainly comes from Vygotsky's theory. There are two very important basic principles in Vygotsky's theory, one of which is to emphasize the social characteristics of learning. In his opinion, collective learning is the process of exploring the content of learning, which is the process of learners' continuous enhancement of their cognition. Another very important principle is the nearest development zone. In dealing with events beyond their ability, students ask a teacher or cooperate with their classmates to complete the activity, which is the development of learning in the nearest area around them.

The background of complete learning experience is to help students understand and construct meaning, and to promote the external scenes of knowledge, skills and experience. It is not only the physical structure of the problem and the concept of structure, but also the intention of the activities and problems embedded in the social environment. In the teaching design, it is the most important link to create a situation conducive to the construction of the meaning of learners. Team work should run through the whole learning process. The collaboration between teachers and students and students and students has a very important role in the collection and analysis of learning materials, the formulation and verification of assumptions, the self-feedback of the learning process and the evaluation of learning outcomes and the final construction of meaning. In a certain sense, collaboration is a sense of consultation. Consultations mainly have self-consultation and mutual consultation. Mutual consultation refers to the discussion and debate between the learning groups. Communication is the most basic way or part of the collaboration process. In fact, the process of collaborative learning is the process of communication. In this process, the idea of each learner is shared by the whole learning community. Communication is a vital means to advance the learning process of each learner. Meaning construction refers to the unique understanding of the nature, the law, and the inner relationship between things. From the perspective of constructivist teaching practice, the construction of meaning is the process of students' knowledge and understanding of knowledge, which is the process of transforming the knowledge imparted by teachers. It is the ultimate goal of teaching process.

\subsection{Analysis of the current situation of piano teaching in Chinese universities}

The teaching of individual courses is the traditional way of piano teaching, and it has a very important position and value in teaching. According to the students' different situations and characteristics, teachers apply effective teaching methods which are suitable for students. In this process, the teacher can grasp the students' understanding of the content of the course, understand the students' acceptance of the teaching content in the course of learning, and guide the students to make progress in their professional skills. The teaching model has its advantages, but there are some shortcomings. It can't concentrate students on teaching. Teachers have to repeat classes, which adds to the burden on teachers and gives them unnecessary labor. It is difficult for students to understand the 
strengths and weaknesses of other students. Teachers spend most of their time on how to improve their students' professional skills. The content of the course is mostly pure technical training, while students spend most of their time practicing skills in the piano room except for class time. It is possible to concentrate and improve efficiency, but it lacks the opportunity to communicate with people.

Piano collective class is a form of teaching for students to attend lectures, practice, play and review. Each class has basically unified teaching plan and teaching content. The teaching materials are novel and original, and the content is extensive and comprehensive. The course has even increased the practice of self-singing, singing, harmony, piano accompaniment and so on. This kind of teaching can overcome the tedium of traditional individual courses, improve the efficiency of study, and increase the opportunity of communication and interaction in the study, thus enhancing the competition of the students. However, the weakness of collective class is that teachers cannot understand the students more fully, and the guidance of students is limited to the general problems of most students. In class teaching, the unity of the progress should be emphasized in the content, which is contradictory with the individual ability, personality and temperament of the students. Piano group teaching is to divide students with similar levels into groups. The teaching form, combined with the content of teaching, and interspersed with group activities, is a guided form of teaching. This form of teaching not only makes full use of and integrates the teaching resources of teachers, but also fully demonstrates the strength and wisdom of the collective. Teachers and students jointly find effective solutions to the difficulties in teaching and learning, and discuss them together, which effectively improves the quality of teaching as a whole.

In traditional piano teaching, teachers communicate and interact with students less. Teachers blindly taught, students blindly imitate and learn, resulting in students lack their own understanding and sentiment. Some teachers do not pay attention to teaching methods and ways of communication in the course of teaching, resulting in students' fear and nervousness, which is very unfavourable to students' learning. The time in class is limited, and the traditional piano teaching often ends a class with repeated difficult skills, and the students learn only a few techniques to deal with it. Classroom interaction is not strong, which seriously affected the teaching effect. It is worthwhile for us to think about how students learn useful knowledge in a limited amount of time. Therefore, the interaction and communication between teachers and students in teaching cannot be ignored. Teachers should strengthen the communication and interaction with students, and explore teaching according to the actual situation. At present, the evaluation method for piano majors is that students play the piano repertoire. Although this evaluation method can directly reflect a student's piano playing level, this single evaluation method has some drawbacks. It is concerned with the final learning outcomes of students and reflects the quantitative data of students' achievements in learning piano and individual differences. This makes it easy for students to develop a mindset. They focus only on a few of the final exams without paying attention to the process of learning and the practical level of learning. It is difficult to achieve the real training goal of teaching. In addition, this evaluation is only a teacher's unilateral assessment. It cannot fully reflect the students' piano learning and learning ability.

\section{Result Analysis and Discussion}

\subsection{The basic situation of the sample}

The questionnaire survey of this study is aimed at a college piano teaching methods to study and evaluate. A total of 14 questions were set up, and the questionnaire design was carried out from the aspects of the teaching methods of the piano teachers in the school, the students' piano learning situation and the freshness of the teachers' classroom teaching. The questionnaire was issued with 300 copies and 287 recycled questionnaires were recovered. The recovery rate was $95.6 \%$. Among them, the effective questionnaire is 275 copies. According to the standard questionnaire, this questionnaire has research value. From the recall of the questionnaire, the sample statistics is as shown in Table 1. 
Table 1 The basic situation of questionnaire samples

\begin{tabular}{|c|c|c|c|}
\hline \multirow{4}{*}{ Major } & Index options & Number of samples & Proportion (\%) \\
\hline \multirow{4}{*}{ Gender } & Pipa major & 77 & $28 \%$ \\
\cline { 2 - 4 } & Piano major & 86 & $31.2 \%$ \\
\cline { 2 - 4 } & Violin major & 63 & $22.9 \%$ \\
\cline { 2 - 4 } & Other & 49 & $17.8 \%$ \\
\hline \multirow{4}{*}{ Grade } & Male & 102 & $37.1 \%$ \\
\cline { 2 - 4 } & Female & 173 & $62.9 \%$ \\
\cline { 2 - 4 } & First grade & 75 & $27.2 \%$ \\
\cline { 2 - 4 } & Second grade & 72 & $26.2 \%$ \\
\cline { 2 - 4 } & Third grade & 53 & $19.4 \%$ \\
\cline { 2 - 4 } & Fourth grade & 41 & $12.9 \%$ \\
\cline { 2 - 4 } & Graduate student & 34 & $12.3 \%$ \\
\hline
\end{tabular}

\subsection{Analysis of teaching methods of piano major}

According to the survey, $21 \%$ of the teachers are satisfied with their own teaching methods in the course of piano teaching, and $37 \%$ of the teachers are not satisfied with their piano teaching methods. This part of the teacher said that this is due to the lack of teaching places and teaching tools, resulting in the piano teaching process is difficult to meet the teaching through a variety of forms of teaching methods. In addition, $42 \%$ of teachers express their current teaching situation. It needs schools to gradually improve on the teaching hardware facilities. The teaching self-evaluation by teachers in university A is shown in Figure 1.

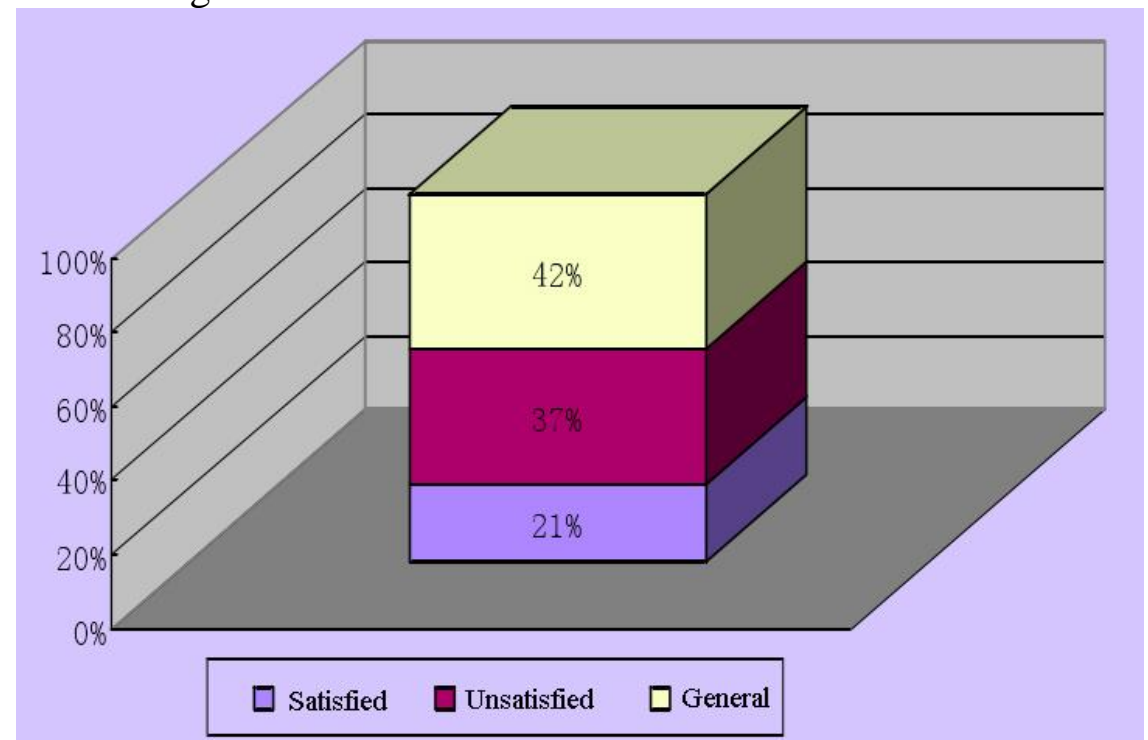

Figure 1 The teaching self-evaluation by teachers in university A

According to the survey, students evaluate the school piano teacher teaching methods. Most students are satisfied with the teaching methods of teachers. In terms of the flexibility of the piano teacher in the process of teaching, only $8 \%$ of the students believe that the piano teacher teaching flexibility, pay attention to cultivate and develop students' thinking ability. However, $45.3 \%$ of the students think that teachers in this area of teaching qualified. it basically meets the students' learning needs. Some students are not satisfied with the teacher's current teaching method, and the proportion of this part is $46.7 \%$. Overall, the students on the current school piano teacher teaching methods also hold great reservations. The teaching self-evaluation by students in university A is shown in Figure 2. 


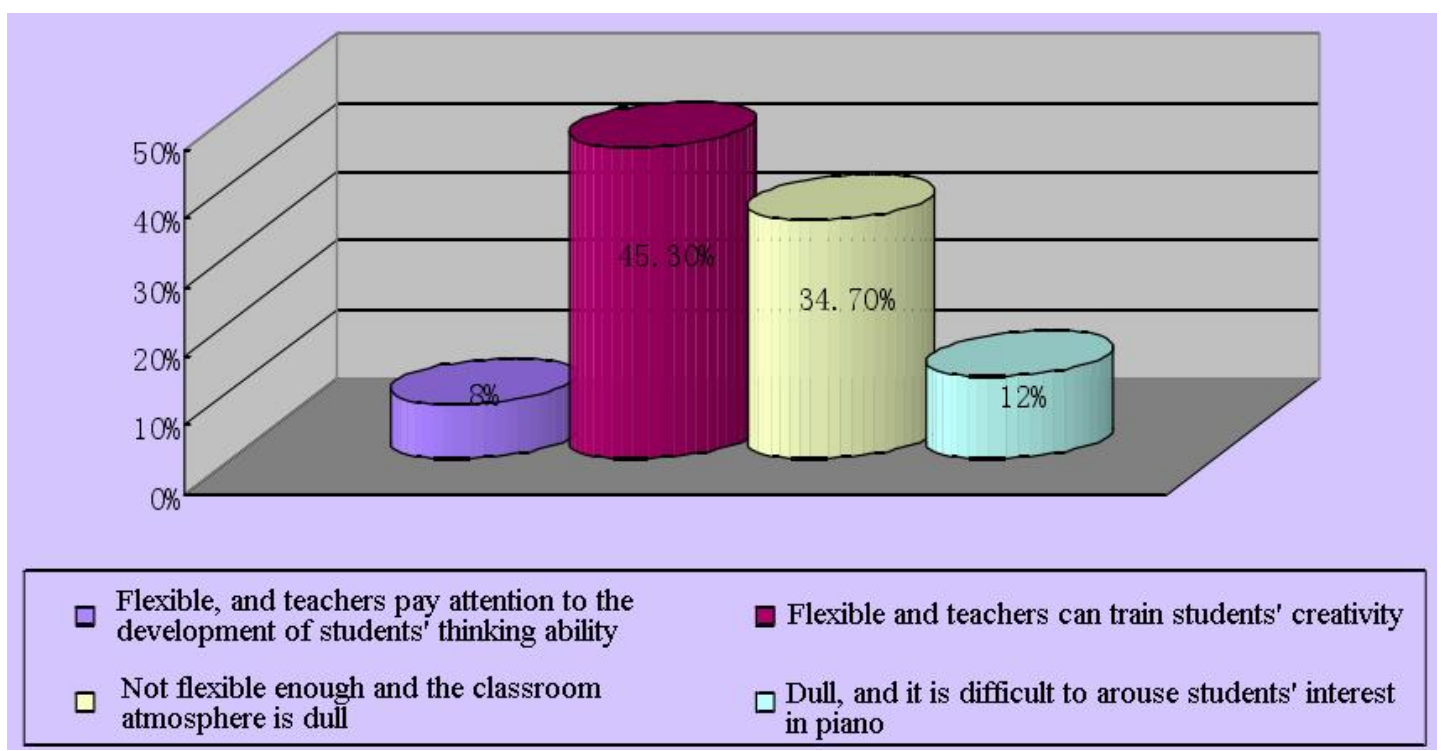

Figure 2 The teaching self-evaluation by students in university A

\subsection{An analysis of the practice of constructivism}

In the course of the investigation, the author makes a questionnaire interview on the students' popularity in the process of piano learning under the guidance of constructivism theory and traditional teaching methods. $70.8 \%$ of students like constructivism. On the one hand, in the course of study, students and teachers can communicate well; on the other hand, students and teachers can establish good relationship between teachers and students. 13\% of students believe that the traditional teaching method is popular. Therefore, it is necessary for college students majoring in music to create an innovative and diverse teaching method to stimulate their enthusiasm for learning. Through the investigation of college students, it reflects a problem from the side. The traditional teaching method has been unable to meet the current piano teaching, which requires the piano teacher continuously explore new teaching mode in the teaching process, to explore new teaching methods, and improve students' level of learning piano. The piano teaching method expected by students in universities is shown in Figure 3.

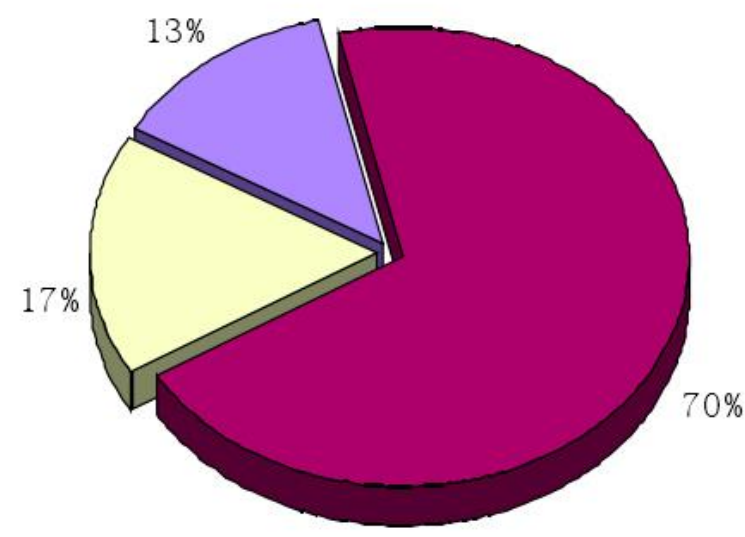

$$
\square \text { traditional } \square \text { constructivism } \square \text { others }
$$

Figure 3 The piano teaching method expected by students in universities

\subsection{Specific countermeasures}

For the abstract and non-concrete perception of music, the cultivation of students' ability to imagine and appreciate can be achieved through the creation of specific situations. This method can enrich students' imaginative ability and improve their musical quality. The use of visual means is an effective way to stimulate students to comprehend the image of music works. For example, multimedia devices are used. Relevant video data were collected on the computer and played by multimedia equipment. When watching video materials, students can not only appreciate the beautiful rhythm, but also 
appreciate the musicians' grasp of the rhythm of music. This leaves a deep impression on the students. In piano teaching, the introduction of paintings can sometimes visualize music. There is a close connection between painting and music, and there is a certain commonality in the field of art appreciation. Musical compositions are abstract. Some paintings can expand the imagination of students, and enable students to quickly integrate into the artistic conception of music, so as to better understand the musical image in the musical works. Through the multimedia equipment, students can understand the music works more directly, and the atmosphere of study is more relaxed and harmonious.

The concept itself has relative stability, and it has comprehensive and leading influence on the development of people and things. Education concept is the core power of constructivism reform. Without the strong cultivation of the guider, the defects of traditional teaching in primary and middle school teaching cannot be changed. Constructivism is the theoretical basis for training teachers, in order to cope with the reform of the new curriculum teaching methods and the ideological change of constructivism. A successful education system is often based on a certain quality of teachers. In the reform of China's educational reform, teachers can make the following two points on the basis of fully understanding the unique development of each student and the real problems in education. First, in the teaching, we should cultivate the students' awareness of autonomy and their sociality as the center. Second, we should take the new democracy as the direction of teaching. In the course of teaching, teachers should be keen to find problems, seek solutions and sum up experience. This is a process of adjusting knowledge structure based on practical problems. The teaching practice brings the flexible skill knowledge and ability which can adapt to the specific educational situation. This is the teacher's unique and effective teaching ability. Constructivism education reform requires teachers to be the facilitator of learning, the reformers of society and the reflective practitioners in the actual teaching.

The dynamics of the curriculum system mainly means that in the curriculum system, teachers and students explore and exchange some educational issues and educational situations around certain learning and development goals. In the teaching practice, teachers should strengthen the rational combination of teaching content and teaching methods, and practice the concept of constructivism in the framework of different knowledge. The content of the teacher education curriculum theory is that learners take the initiative to accumulate relevant content and understand it and form subjective experience. Teaching is more than just passing on knowledge. Students also enrich their experience when they accept knowledge. The combination of theoretical content and practical experience is the professional literacy that teachers need now. Students are always the core of teaching. Teachers should guide students to develop the habit of autonomous learning, to encourage students to doubt their own concepts, and to seek exploration, so that students can work toward their ideals and aspirations. In the course of teaching, teachers should pay attention to the knowledge reserves and experience that students already have. At the same time, different levels of students will affect their future self-confidence, so under the difference, teachers also need to pay attention to and resolve the students in the initial stage of inferiority complex. Teachers should arouse their enthusiasm. For example, give students success evaluation. Students who are always feeling difficult to learn will have a sense of frustration. Piano majors have a closer relationship with their teachers in class than other majors. In class, teachers should try to develop teaching democracy and provide opportunities for successful and progressive students at different levels.

\section{Conclusion}

To sum up, the constructivism teaching theory provides sufficient theoretical basis for piano teaching in colleges and universities. The twenty-first century is the era of knowledge innovation. As a music educator, the traditional music teaching mode and repetitive skills training cannot meet the needs of social development. College piano teaching should cultivate professional qualified and comprehensive high-quality music talent. We need to update the traditional piano education philosophy, reform the teaching behavior and transform the role of teachers, so as to construct a 
student-centered teaching philosophy. This idea advocates independent learning ability, thinking ability and creativity. It emphasizes the student's dominant position. This can get rid of the negative influence of the traditional educational thoughts, arouse the students' interest and enthusiasm, and cultivate the students' more comprehensive musical ability, so as to meet the demand of modern society for music talents. At present, China's education has many differences in the region, and the development is imbalanced. Each school also has differences in educational resources, students and teachers. Therefore, the specific implementation process needs to combine the actual situation of the school, the region and the piano teaching.

\section{References}

[1] Cleaver, D., \& Ballantyne, J. (2014). Teachers' views of constructivist theory: A qualitative study illuminating relationships between epistemological understanding and music teaching practice. International Journal of Music Education, 32(2), 228-241.

[2] Doolittle, P. E. (2014). Complex Constructivism: A Theoretical Model of Complexity and Cognition. International Journal of teaching and learning in higher education, 26(3), 485-498.

[3] Harrington, S. A., Bosch, M. V., Schoofs, N., Beel-Bates, C., \& Anderson, K. (2015). Quantitative outcomes for nursing students in a flipped classroom. Nursing Education Perspectives, 36(3), $179-181$.

[4] Jin, Y. (2015). Influence of Information Technology on College Piano Course Teaching Model. Journal of Digital Information Management, 13(3), 185.

[5] Lang, L. I. (2015). Research on Application of Multimedia Technology to Piano Teaching in Universities and Colleges. Studies in Sociology of Science, 6(5), 48-52.

[6] Laroche, J., \& Kaddouch, I. (2014). Enacting teaching and learning in the interaction process:"Keys" for developing skills in piano lessons through four-hand improvisations. Journal of Pedagogy, 5(1), 24-47.

[7] López-Íñiguez, G., Pozo, J. I., \& de Dios, M. J. (2014). The older, the wiser? Profiles of string instrument teachers with different experience according to their conceptions of teaching, learning, and evaluation. Psychology of Music, 42(2), 157-176.

[8] Pike, P. D. (2014). The differences between novice and expert group-piano teaching strategies: A case study and comparison of beginning group piano classes. International Journal of Music Education, 32(2), 213-227.

[9] Parkinson, T. (2016). Mastery, enjoyment, tradition and innovation: A reflective practice model for instrumental and vocal teachers. International Journal of Music Education, 34(3), 352-368.

[10] Simones, L., Schroeder, F., \& Rodger, M. (2015). Categorizations of physical gesture in piano teaching: A preliminary enquiry. Psychology of Music, 43(1), 103-121.

[11] Teo, T., \& Zhou, M. (2017). The influence of teachers' conceptions of teaching and learning on their technology acceptance. Interactive Learning Environments, 25(4), 513-527. 